\title{
Molecular screening for Epstein Barr virus (EBV) among Sudanese patients with nasopharyngeal carcinoma (NPC)
}

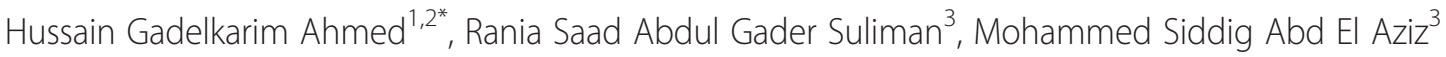 \\ and Fawaz D Alshammari ${ }^{4}$
}

\begin{abstract}
Objective: The aim of this study was to screen for the presence of Epstein Barr Virus (EBV) among Sudanese patients with Nasopharyngeal Carcinoma (NPC).

Methods: In this study, 150 tissue samples that were previously diagnosed as having NPC were screened for the presence of EBV using Polymerase Chain Reaction (PCR). PCR was performed to amplify two viral genes; EBV nuclear antigen-4 (EBNA-4) and latent membrane protein-1 (LMP1).
\end{abstract}

Results: EBV genes were detected in 92/150 (61.3\%) tissue samples. Of the 92 infected samples, 58/92 (63\%) were found among males and 34/92 (37\%) were among females.

Conclusion: EBV is prevalent in the Sudan and responsible of the vast majority of cases of NPC.

Keywords: Epstein barr virus, Nasopharyngeal carcinoma, Sudan

\section{Introduction}

NPC is the most common cancer arising from the nasopharynx that varies significantly from other cancers of the head and neck in its occurrence, causes, clinical behavior, and treatment [1].

NPC is infrequent in the United States and many other countries, representing less than 1 case per 100,000 in most populations, but is exceptionally common in southern regions of China [2], mainly in Guangdong, accounting for $18 \%$ of all cancers in China [3]. The etiology of NPC is multifactorial with race, genetics, environment and EBV as a major risk factor. While rare in Caucasian populations, it is one of the most common nasopharyngeal cancers in Chinese, and has endemic clusters in Alaskan Eskimos, Indians, and Aleuts. Remarkably, as native-born Chinese migrate, the incidence diminishes

\footnotetext{
* Correspondence: hussaingad1972@yahoo.com

'Department of Pathology, College of Medicine, Molecular Diagnostics and Personalized Therapeutics Unit, University of Hail, Hail, Kingdom of Saudi Arabia

${ }^{2}$ Department of Histopathology and Cytology, FMLS, University of Khartoum, Hail, Sudan

Full list of author information is available at the end of the article
}

in successive generations, although still higher than the native population [4].

NPC caused by an interaction between infection with EBV and environmental and genetic factors, encompassing a multistep oncogenic process [5]. EBV has worldwide dissemination, infecting over $95 \%$ of the adult population worldwide [6]. In some parts of Asia, $80 \%$ of children are infected by 6 years of age, and almost $100 \%$ have seroconverted by 10 years of age [7]. Although primary EBV infection is characteristically sub-clinical, the virus is linked to the later progress of numerous malignancies, including NPC [3]. The virus is transmitted by saliva, and its primary infection occurs during childhood with replication of the virus in the oropharyngeal lining epithelial cells, followed by a latent infection of B lymphocytes (primary target of EBV). High titers of EBV-related antigens (specifically of IgA class), a latent EBV infection recognized in neoplastic cells of almost all cases of NPC. Moreover, the clonal EBV genome constantly identified in invasive carcinomas and high-grade dysplastic lesions propose a critical role of EBV in the pathogenesis of NPC in 
endemic areas $[7,8]$. Therefore, the aim of this study was to screen for EBV among Sudanese patients with NPC.

For identification of EBV we demonstrated EpsteinBarr nuclear antigen 1 (EBNA1) and Epstein-Barr virus latent membrane protein 1 (LMP1) EBV genes. EBNA1 is a multifunctional, dimeric viral protein associated with EBV [9]. It is the only EBV protein found in all EBV-related malignancies [10]. LMP1 is the best-documented oncoprotein of the EBV latent gene products, as it is expressed in most EBV-related human cancers [11].

\section{Methods}

In this study, 150 formalin fixed paraffin wax processed tissue samples of nasopharyngeal carcinoma were obtained from previously operated patients from different histopathology laboratories in Khartoum State, Sudan. All tissue samples were from those who had not yet given anti-cancer therapy. The study was approved by the Ethical Committee of the Research Board of Faculty of Medical Laboratory Science, Sudan University for Science and Technology, Khartoum, Sudan.

\section{DNA extraction}

DNA was extracted from paraffin-embedded samples, by immersing tissue section in xylene to dissolve the paraffin from the tissue, and then rehydrated using a series of ethanol washes. Proteins and harmful enzymes such as nucleases were digested by proteinase K. Buffer containing denaturing agent (sodium dodecyl sulfate (SDS)), was added to facilitate digestion [12]. Nucleic acids were purified from the tissue lysate using buffersaturated phenol and high speed centrifugation. Following phenol extractions, RNase A was added to eliminate contaminating RNA. Additional phenol extractions following incubation with RNase A were used to remove any remaining enzyme. Sodium acetate and isopropanol were added to precipitate DNA, and high speed centrifugation was used to pellet the DNA and facilitate isopropanol removal. Washing with $70 \%$ ethanol was performed to remove excess salts, followed by centrifugation to re-pellet the DNA [13,14]. DNA is resuspended in distilled water, quantified and stored at $-20^{\circ} \mathrm{C}$ Purified DNA was subsequently used in downstream applications of PCR.

\section{DNA quantification}

To evaluate the DNA quantification after DNA extraction, we had analyzed DNA measurement using a NanoDrop spectrophotometer.
PCR

EBV genome was detected by PCR using two primers that targets EBV nuclear antigen-4 (EBNA-4) 5'-GAG GAGGAAGACAAGAGTGG and 5'GATTCAGGCGT GGTCCTTGG 3' and latent membrane protein-1 (LMP1) 5'CCGAAGAGGTTGAAAACAAA3' and 5'GTGGGG GTCGTCATCATCTC 3'.

Any case detected EBNA-4 and/or LMP-1was considered positive indicating the presence of EBV.

\section{Molecular identification by polymerase chain reaction}

Polymerase chain reaction (PCR) was carried out for amplification of target EBV genome by using genomic DNA template (1.5 L of EBV detection). PCR was performed in a total volume of $23 \mathrm{~L}$ for EBV. Master mix that contained $1 \mathrm{~L}$ of $10 \mathrm{mM}$ dNTP mixed $(2.5 \mathrm{mM}$ dATP, $2.5 \mathrm{mM}$ dGTP, $2.5 \mathrm{mM}$ dCTP, and $2.5 \mathrm{mM}$ dTTP), $1.5 \mathrm{~L}$ of $25 \mathrm{mM} \mathrm{MgCl} 2,2.5 \mathrm{~L}$ of 10 PCR buffer (10 m MTrisHCl [pH 8.3], $50 \mathrm{mM} \mathrm{KCl),} 1 \mathrm{~L}$ Taq polymerase (approximately $1 \mathrm{U}$ ), $1.5 \mathrm{~L}$ forward primer and $1.5 \mathrm{~L}$ reverse primer. Volume was completed to $25 \mathrm{~L}$ per reaction mixed with doubled distilled water $\left(\mathrm{ddH}_{2} \mathrm{O}\right)$. The master mix of all samples was mixed by vortexing in a sterile $0.2-\mathrm{mL}$ PCR tube. Amplification was then set in an initial denaturation stage at $94^{\circ} \mathrm{C}$ for 5 minutes, then 30 cycles of $94^{\circ} \mathrm{C}$ for 30 seconds, and annealing at $55^{\circ} \mathrm{C}$ for 30 seconds, followed by ex- tension at $72^{\circ} \mathrm{C}$ for 90 seconds and a final extension stage at $72^{\circ} \mathrm{C}$ for 5 minutes.

\section{Ethical consent}

The study was approved by Faculty Research Board, Faculty of Medical Laboratory Science, Sudan University for Science and Technology. This in addition to the fact that, the authors followed the tenants of the Declaration of Helsinki.

\section{Results}

In this study we investigated 150 formalin fixed paraffin wax tissue blocks obtained from patients previously diagnosed with nasopharyngeal carcinoma, their ages ranging from 17 to 88 years with a mean age of 51 years. Male/female ratio was 1:83 to 1.00. Of the 150 NPC tissue specimens, EBV was identified in 92/ $150(61.3 \%)$ samples and couldn't be identified in 58/ $150(38.7 \%)$ tissue samples. Out of the 92 infected samples, 58/97 (60\%) were found among males and 34/53 (64\%) were found among females. The $95 \%$ confidence interval and the odd ratio for sex male/female was $0.831(0.416-1.661), \mathrm{P}<0.365$, as indicated in Figure 1.

As shown in Table 1, the highest frequency of infection rates were seen among age group 31-45 years representing 23/92 (25\%) followed by age range 46-60 


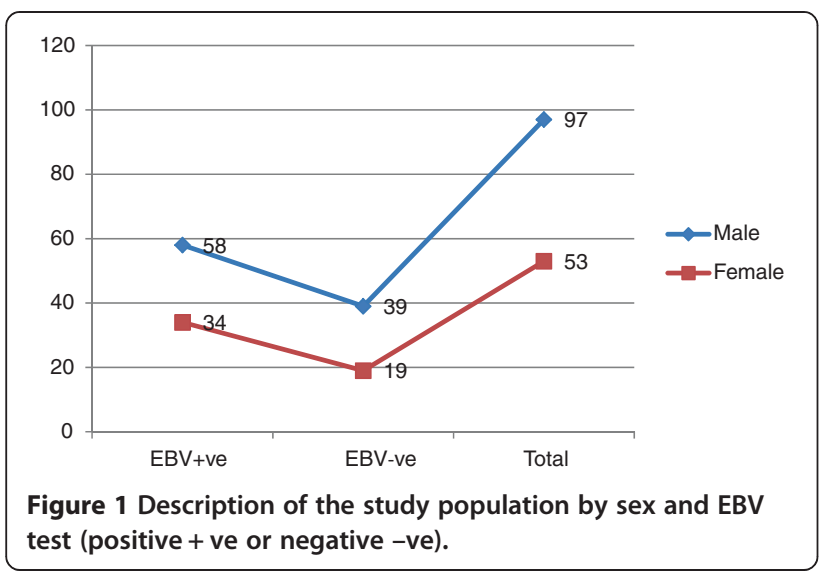

and 61-75 years, constituting 22/92 (23.9\%) for each, then $<30$ years and $71+$ representing $18 / 92(19.5 \%)$ and $7 / 92(7.6 \%)$, in this order. Nevertheless, when calculating the percentage in each group, the greatest proportion of infection was found in age group 31-45 years constituting $70 \%$ followed by $61-75,31-45,<30$ and $76+$ years, representing $61 \%, 60 \%, 59 \%$ and $50 \%$, respectively, as indicated in Figure 2.

In respect to the residence, most of cases of NPC were coming from Western Sudan representing 55/150 (36.7\%) followed by Southern Sudan constituting 29/150 (19.3\%), as shown in Figure 3. In regard to the residence and EBV infection, the great majority of infections were identified among Western populations, representing 35/ 92 (38\%) followed by Khartoum, (Eastern and Sothern), and Northern constituting 17/92 (18.5\%), 15/92 (16.3\%), and 10/92 (10.8\%), respectively, as shown in Table 2. However, when calculating the percentage within individual entire residence, the utmost proportion of infection was found in the East representing $71.4 \%$ followed by West, Khartoum, North and South constituting $63.6 \%, 63 \%, 55.6 \%$ and $51.7 \%$, in this order, as indicated in Figure 4.

\section{Discussion}

As in many malignant tumors, NPC development reflects the multifarious interaction between host genes

Table 1 Distribution of the study population by age and EBV infection

\begin{tabular}{lllllll}
\hline EBV & $<\mathbf{3 0}$ years & $\mathbf{3 1 - 4 5}$ & $\mathbf{4 6 - 6 0}$ & $\mathbf{6 1 - 7 5}$ & $\mathbf{7 6 +}$ & Total \\
\hline +ve & 18 & 23 & 22 & 22 & 7 & 92 \\
-ve & 12 & 10 & 15 & 14 & 7 & 58 \\
Total & 30 & 33 & 37 & 36 & 14 & 150 \\
\hline
\end{tabular}

and environmental factors, but the crucial role of EBV infection delivers key vision into the etiology of this tumor. In this study, the correlation between NPC and the existence of the EBV genome was examined. An extremely significant positive correlation was found based on two genes encoding for EBV viral proteins. A number of studies have studied this correlation, but findings are greatly contradictory. The bulk of these studies reported a wide range of frequencies for the presence of EBV in NPC [15-17]. Many studies have investigated the association between EBV infection and nasopharyngeal carcinogenesis development [18]. The prevalence of histology types are different comparing endemic and non-endemic regions. In endemic areas, Type III represents over 97\% of the cases, while the keratinizing type is more common in western countries $(\sim 75 \%)[19,20]$.

However, the role of EBV infection in the etiology of NPC in Sudan had been reported since 1979 [21], but none of these old studies have used molecular identification of the virus. A recent a study has investigated 43 biopsies obtained from Sudanese patients with NPC for the presence of EBV using EBER-ISH. Ten normal samples were used to assess the presence of the virus in non-cancer tissues. All nasopharyngeal carcinoma biopsies $(100 \%)$ were positive for EBER1 in almost all carcinoma cells. No hybridization was observed in all 10 non-cancer tissues [22]. These findings greatly differ from our obtained prevalence of EBV in the present study $(61.4 \%)$ and this might be attributed to their small sample size 43 compared to our sample size 150 tissue samples. Inconsistencies in detection efficacy may also be due to technical variances or variation between NPC subgroups. Usually, PCR is valuable in the detection of EBV in a certain cancer, but it might not be suitable for identifying the association between the virus and the particular type of cancer. However, Adam et al. applied EBV-encoded RNA (EBER) in Situ hybridization (EBER-ISH). The EBER-ISH is a novel method for precise detection of the EBV genome in the nuclei of tumor cells [23]. EBER-ISH has reported to have a sensitivity of $98 \%$ and a specificity of $100 \%$ in detecting primary NPC [16]. In the present study, all tissue samples were including not only tumor cells but also tumor infiltrating lymphocytes were investigated in PCR. However, EBV DNA may occasionally be detected in non-neoplastic nasopharyngeal tissues, particularly in ISH-negative cases probably reflect a lower sensitivity than PCR, particularly when a small number of viral copies are present [24]. Notably, a study applied ISH method, no virus was detected in the normal lymphocyte and epithelium surrounding the tumor [16].

Nevertheless, there are other studies reporting conflicting findings in other cancer types. Of these studies EBV was detected in 118/175 (67.4\%) oral brush samples from apparently healthy volunteers and 69/217 


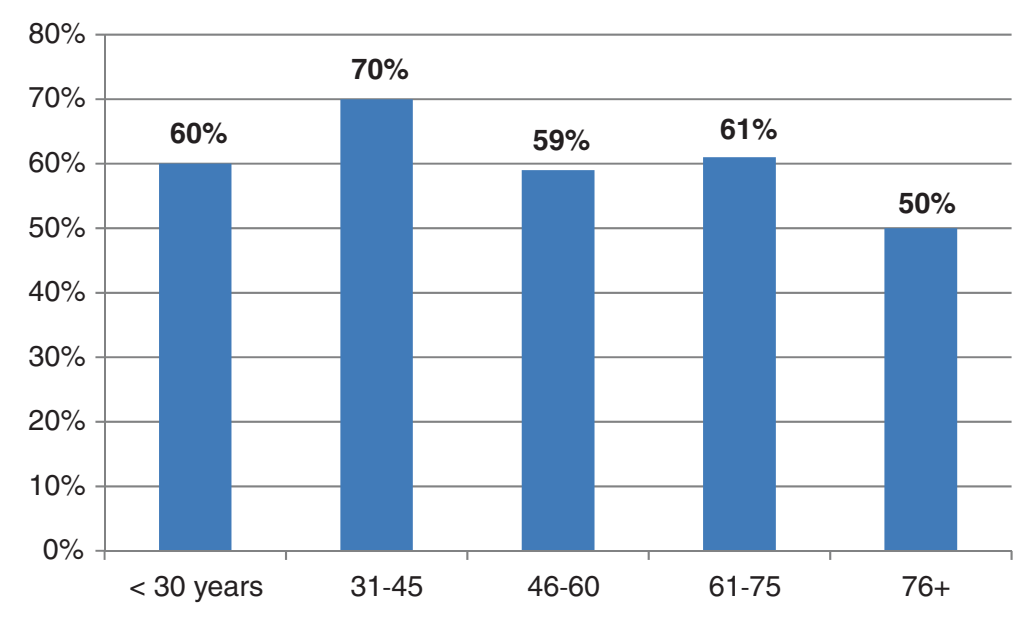

Figure 2 Description of percentage of EBV positive test in each age group.

(31.8\%) of patients with oral cancer [25]. EBV LMP1 gene transcripts were found in 29 (36.3\%) of the 80 patients with leukemia but in none of the healthy controls $(\mathrm{P}<.0001)$ [26]. EBV genome was detected in 55.5\% ( $\mathrm{n}=$ 90) of breast cancer tissues as compared to $23 \%$ in control tissue samples $(\mathrm{p}=0.0001)$ [27].

Regarding sex, the number of males with NPC was higher than females, and this has been previously reported from Sudan [28,29]. Moreover, in this study, though the frequency of EBV infection was higher among males but when comparing the percentage of EBV infection within each group, women (64\%) were relatively infected more than men (60\%). Several studies have shown that NPC is more often diagnosed in men than in women, and tends to occur at an earlier age than do most cancers [30-32].

In this study, the infection was detected in relatively high numbers of patients at earlier adults' age range. On the other hand most studies investigated relationship between EBV and gender; they found the proportion of infection is greater among men than women [33]. A previous study from Sudan have reported that NPC tended to occur in younger patients (youngest, 3 years), with 14 and $12.1 \%$ of cases in children 14 years or under in the Sudan Cancer Register and Radiation

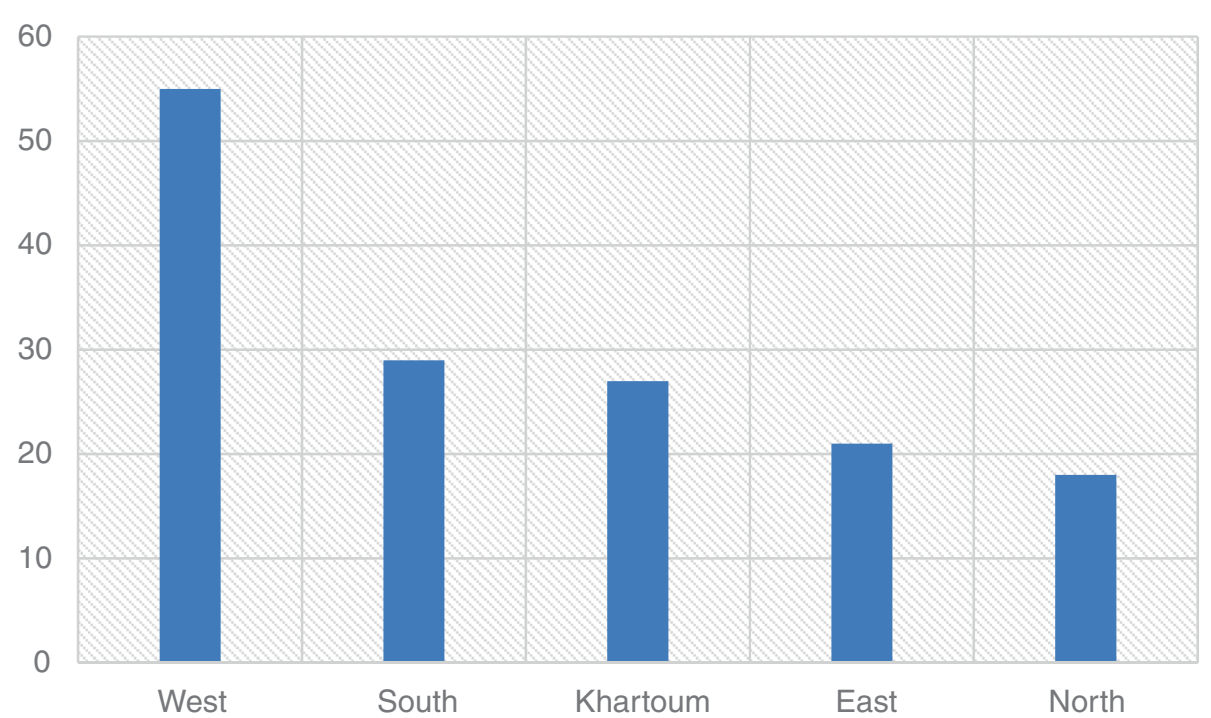

Figure 3 Description of residence by NPC. 
Table 2 Distribution of the study population by residence and EBV infection

\begin{tabular}{llll}
\hline Residence & $\begin{array}{l}\text { EBV } \\
\text { positive }\end{array}$ & Negative & Total \\
\hline West & 35 & 20 & 55 \\
Khartoum & 17 & 10 & 27 \\
East & 15 & 6 & 21 \\
South & 15 & 14 & 29 \\
North & 10 & 8 & 18 \\
Total & 92 & 58 & 150 \\
\hline
\end{tabular}

and Isotope Centre, Khartoum, respectively; it is the commonest childhood malignancy in the Sudan [28]. The association between age and presence NPC and EBV infection might be attributed to the early exposure to the virus which may somehow be linked to Burkitt's lymphoma and its link to factors enhancing EBV infection. We mean the intense growing of Milk Bush (Euphorbia) particularly in the western parts of Sudan, which accelerate chance of infection with EBV.

According to the residence, most of cases of NPC in the present study were from Western Sudan, although Khartoum hosts the bulk of population with wide spectrum of ethnic diversity. An earlier study has reported high frequencies of NPC from Western Sudan, particularly, areas surrounding Nuba Mountains in Kordofan State [29]. However, they attributed that to the high background radiation due to naturally produced radioactive uranium rather than EBV infection. Geological studies revealed that radiation exposure rates around the Nuba Mountains are among the highest in the world in regard to background radiation. Radiation exposure in the Nuba Mountains is chiefly due to uranium, a byproduct of usable rock phosphate fertilizers $[34,35]$. Nevertheless, when comparing the proportions of EBV infection within each geographical residence, the highest percentage was observed among those coming from Eastern Sudan. A previous study from Sudan, studied the epidemiology and etiology of NPC has revealed that, the ethnic and geographical distribution of the cases showed that racial susceptibility played a significant role in the etiology of NPC in the Sudan with EBV as an exciting factor [28].

Nevertheless, and due to paucity of data and registry, the only epidemiological available report return to 1983 in which, 374 cases of NPC were recorded in the Sudan Cancer Registry (SCR) and 512 cases were seen at the Radiation and Isotope Centre, Khartoum (RICK)d. NPC formed $5.8 \%$ of all cancer cases in the SCR and $7.2 \%$ at the RICK; this is the highest frequency so far reported outside the Chinese at that time [28]. However, the current prevalence is expected to be high, particularly with increasing cases of Burkitt lymphoma in Sudan, though the reports in this context are very old. During the period 1962-73 twenty-nine cases of Burkitt's lymphoma were seen and examined histologically in Khartoum, Sudan. Burkitt's lymphoma formed $20 \%$ of the cases of childhood lymphomas [36].

In conclusion, the present study providing strong evidence supporting the etiologic role for EBV infection in NPC in Sudan. The relationship between age at onset of NPC, ethnic factors, geographical distribution and EBV infection requires further investigations. The

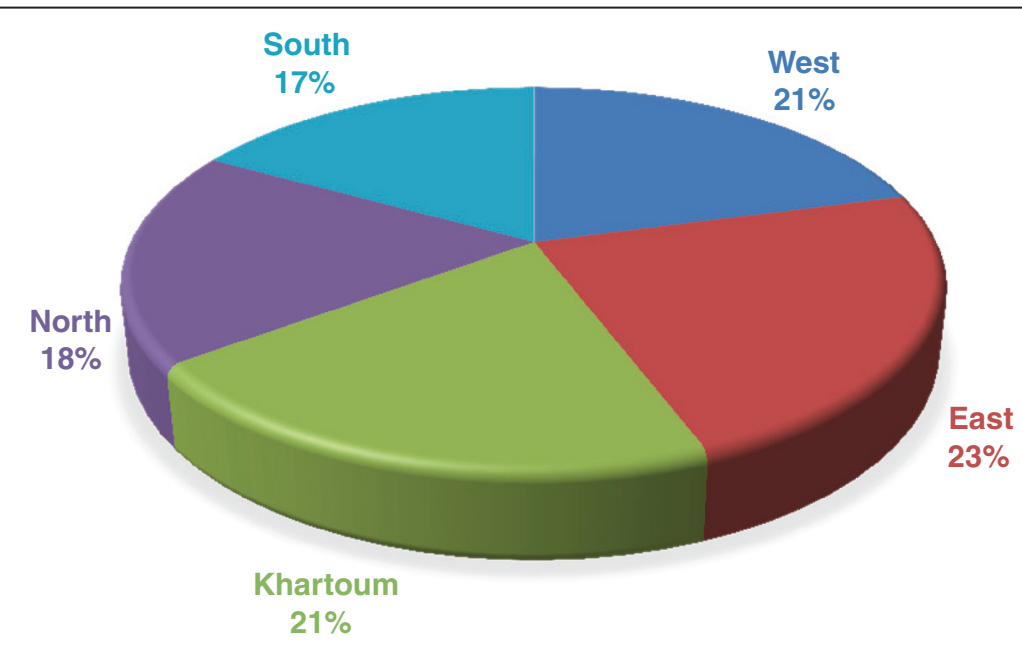

Figure 4 Description of study population by residence and EBV infection. 
outcomes of this study can be further utilized in terms of the new approaches in EBV vaccination and therapeutic consequences.

\section{Competing interests}

The authors declare that they have no competing interests.

\section{Authors' contribution}

HGA: Study design, data analysis, manuscript preparation. RSAS: Data Collection and Molecular identification. MSA: Data Collection and Molecular identification. FDA:data analysis, manuscript preparation. All authors read and approved the final manuscript.

\section{Acknowledgments}

The authors would like to thank people at histopathology at Radio Isotope Centre Khartoum for helping in the sample collection and Prof. Fahd Z. Eissa for revising the manuscript.

\section{Author details}

${ }^{1}$ Department of Pathology, College of Medicine, Molecular Diagnostics and Personalized Therapeutics Unit, University of Hail, Hail, Kingdom of Saudi Arabia. ${ }^{2}$ Department of Histopathology and Cytology, FMLS, University of Khartoum, Hail, Sudan. ${ }^{3}$ Department of Histopathology and Cytology, Faculty of Medical Laboratory Science, Sudan University for Science and Technology, Khartoum, Sudan. ${ }^{4}$ Department of Medical Laboratory Science, College of Applied Medical Science, University of Hail, Hail, Kingdom of Saudi Arabia.

\section{Received: 21 November 2014 Accepted: 3 February 2015}

\section{Published online: 17 February 2015}

\section{References}

1. Pingpin W, Man N, Suming P, Yanhong Z, Cijun S, Jing W, et al. Cancer stem-like cell: a novel target for nasopharyngeal carcinoma therapy. Stem Cell Res Ther. 2014;5:44.

2. $\quad$ Fang W, Li X, Jiang Q. Transcriptional patterns, biomarkers and pathways characterizing nasopharyngeal carcinoma of Southern China. J Transl Med. 2008:6:32.

3. Chang ET, Adami HO. The Enigmatic Epidemiology of Nasopharyngeal Carcinoma. Cancer Epidemiol Biomarkers Prev. 2006;15(10):1765-77.

4. Thompson LDR. Update on Nasopharyngeal Carcinoma. Head Neck Pathol. 2007:1(1):81-6.

5. Zhou X, Cui J, Kajdacsy-Balla AA, Ye H, Wang J, Rao PN. The progress on genetic analysis of nasopharyngeal carcinoma. Comp Funct Genomics. 2007:2007, Article ID 57513

6. Rickinson AB, Kieff E. Epstein-Barr virus. In: Knipe DM, Howley PM, editors Field's virology. 4th ed. Philadelphia: Lippincott Williams \& Wilkins; 2001. p. 2575-627.

7. Kangro HO, Osman HK, Lau YL, Heath RB, Yeung CY, Ng MH. Seroprevalence of antibodies to human herpesviruses in England and Hong Kong. J Med Virol. 1994:43(1):91-6.

8. Lun SW, Cheung ST, Lo KW. Cancer stem-like cells in Epstein-Barr virusassociated nasopharyngeal carcinoma. Chin J Cancer. 2014;33(11):529-38.

9. Humme S, Reisbach $G$, Feederle $R$, et al. The EBV nuclear antigen 1 (EBNA1) enhances B cell immortalization several thousand fold. Proc Natl Acad Sci U S A. 2003:100(19):10989-94.

10. Duellman Sarah J, Katie L, Thompson Joshua J. Coon, Richard R Burgess. "Phosphorylation sites of Epstein-Barr Virus EBNA1 regulate its function" J Gen Virol. 2009;90(9):2251-9.

11. Ersing I, Bernhardt K, Gewurz BE. NF-KB and IRF7 pathway activation by Epstein-Barr virus Latent Membrane Protein 1. Viruses. 2013;5:1587-606. 6 ed.

12. Hilz $H$, Wiegers $U$, Adamietz P. Stimulation of proteinase $K$ action by denaturing agents: application to the isolation of nucleic acids and the degradation of 'masked' proteins. Eur J Biochem. 1975:56:103-8.

13. Joseph Sambrook DR. Molecular Cloning: A Laboratory Manual. New York: Cold Spring Harbor Laboratory Press, Cold Spring Harbor; 2001.

14. Pikor LA, Enfield KSS, Cameron H, Lam WL. DNA extraction from paraffin embedded material for genetic and epigenetic analyses. J Vis Exp. 2011;49: e2763.

15. Le Roux F, Joab I. Epstein-Barr virus and nasopharyngeal carcinoma. EpsteinBarr Virus Rep. 1998:5:53-7.
16. Tsai ST, Jin YT, Mann RB, et al. Epstein-Barr virus detection in nasopharyngeal tissues of patients with suspected nasopharyngeal carcinoma. Cancer. 1998:82:1449-53.

17. Bar-Sela G, Kuten A, Minkov I, Gov-Ari E, Ben-Izhak O. Prevalence and relevance of EBV latency in nasopharyngeal carcinoma in Israel. J Clin Pathol. 2004:57(3):290-3.

18. Spano JP, Busson P, Atlan D, Bourhis J, Pignon JP, Esteban C, et al. Nasopharyngeal carcinomas: an update. Eur J Cancer. 2003;39:2121-35.

19. Marks JE, Phillips J, Menck HR. The National Cancer Data Base report on the relationship of race and national origin to the histology of nasopharyngeal carcinoma. Cancer. 1998;83:582-8.

20. Raab-Traub N. Epstein-Barr virus in the pathogenesis of NPC. Semin Cancer Biol. 2002;12(6):431-41.

21. Malik MO, Banatvala J, Hutt MS, Abu-Sin AY, Hidaytallah A, El-Hadi AE. Epstein-Barr virus antibodies in Sudanese patients with nasopharyngeal carcinoma: a preliminary report. J Natl Cancer Inst. 1979;62(2):221-4.

22. Adam AAM, Abdullah NE, Lamyaa El Hassan LAM, Elamin EM, Ibrahim ME, El-Hassan AM. Detection of Epstein-Barr Virus in Nasopharyngeal Carcinoma in Sudanese by in Situ Hybridization. J Cancer Ther. 2014;5:517-22.

23. Howe JG, Shu MD. Isolation and characterization of the genes for two small RNAs of Herpesvirus papio and their comparison with Epstein-Barr VirusEncoded EBER RNAs. J Virol. 1988:62:2790-8.

24. Vera-Sempere F, Burgos J, Botella MS, Morera C. Comparative analysis of Epstein-Barr virus (EBV) detection by nested-PCR and non-isotopic in situ hybridization in nasopharyngeal carcinoma (NPC). Clin Chim Acta. 1998:271(2):119-32.

25. Jalouli J, Ibrahim SO, Sapkota D, Jalouli MM, Vasstrand EN, Hirsch JM, et al. Presence of human papilloma virus, herpes simplex virus and Epstein-Barr virus DNA in oral biopsies from Sudanese patients with regard to toombak use. J Oral Pathol Med. 2010;39(8):599-604.

26. Ahmed HG, Osman SI, Ashankyty IM. Incidence of Epstein-Barr virus in pediatric leukemia in the Sudan. Clin Lymphoma Myeloma Leuk. 2012:12(2):127-31

27. Yahia ZA, Adam AA, Elgizouli M, Hussein A, Masri MA, Kamal M, et al. Epstein Barr virus: a prime candidate of breast cancer aetiology in Sudanese patients. Infect Agent Cancer. 2014;9(1):9.

28. Hidayatalla A, Malik MO, El Hadi AE, Osman AA, Hutt MS. Studies on nasopharyngeal carcinoma in the Sudan-I. Epidemiology and Aetiology. Eur J Cancer Clin Oncol. 1983;19(6):705-10.

29. Abdullah NE, Adam AAM, Khalifa EH, Hassan LAM, Ibrahim ME, Hamad KM, et al. Nasopharyngeal cancer in Sudan: epidemiology, clinical and histological characteristics. Clin Med Insights Ear Nose Throat. 2011;4:5-11.

30. Ferlay J, Parkin DM, Curado MP, Bray F, Edwards B, Shin HR, et al. Cancer Incidence in Five Continents, Volumes I to IX: IARC Cancer Base No. 9 [Internet]. Lyon: International Agency for Research on Cancer; 2010.

31. Guangli X, Yabing C, Xibin Q, Weihua W, Yufeng W. Influence of gender and age on the survival of patients with nasopharyngeal carcinoma. BMC Cancer. 2013:13:226.

32. Hiu-Ying L, Chit-Ming L, Yap-Hang C, et al. Secular trends of salted fish consumption and nasopharyngeal carcinoma: a multi-jurisdiction ecological study in 8 regions from 3 continents. BMC Cancer. 2013;13:298.

33. Tomita $Y$, Ohsawa M, Kanno H, et al. Epstein-Barr virus in Hodgkin's disease patients in Japan. Cancer. 1996:77(1):186-92.

34. Ati Sadig Abdel, Ahmed Yousif M, Charbonneau BW, Lecheminant GM. The Uro radiometric anomaly - uraniferous phosphate in a tectonic breccia (Nuba Mountains, Kordofan Province, Sudan). Uranium. 1988;4(24):351-63.

35. Sam AK, Ahmed MMO, El Khangi FA, et al. Radiological and chemical assessment of Uro and Kurum rock phosphates. J Environ Radioact. 1999;42:65-75.

36. Veress B, Malik MO, Satir AA, El Hassan AM. Burkitt's lymphoma in the Sudan. Afr J Med Med Sci. 1976:5(2):115-9. 